\title{
Avaliação de um Evento Reumatológico: Qual é o Significado?
}

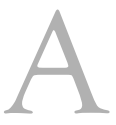

noção de mensuração é crucial para as ciências. $\mathrm{E}$ a correspondência entre uma sociedade e seus associados depende, em parte, do provimento e troca de informações precisas. Porém, quem deve fornecêlas? Não tem sido hábito proceder à análise de eventos médicos e posterior publicação de seus resultados, obtendose, assim, dados importantes e significativos para definir e elaborar os acontecimentos vindouros.

Durante a XVII Jornada Brasileira de Reumatologia e XVII Jornada Norte/Nordeste de Reumatologia, foi distribuído entre os participantes um questionário padronizado para se avaliar: o perfil do reumatologista; o Estado de procedência; a razão de sua participação; a localização do evento; a organização geral; a qualidade educacional; a qualidade científica; a qualidade das conferências; a qualidade dos pôsteres; a qualidade dos simpósios satélites; o livro da programação final; participação com pôster; o breakfast científico.

Não há um instrumento único para se avaliar um evento médico. A escolha do questionário, portanto, é importante e deve estar condicionada às finalidades do estudo.

Um instrumento deve mensurar o grau de um atributo com a finalidade de distingui-lo entre indivíduos. Elaborou-se um questionário simples, auto-aplicável, cujo propósito foi revelar a percepção dos reumatologistas sobre os eventos (Anexo 1).

Esse questionário, incluído no material distribuído durante as jornadas, dispõe respostas de múltipla escolha, de forma a refletir a natureza da perspectiva de quem responde sobre o desejo do que está sendo perguntado ${ }^{(1)}$ : o que as pessoas dizem querer.

O critério de inclusão foi o da totalidade de participantes das jornadas. Não foi utilizado nenhum critério de exclusão.

A análise estatística foi do tipo descritiva, utilizando-se o pacote Epi-info.

Como resultados, obteve-se apenas 60 questionários respondidos por completo e entregues na secretaria executiva das Jornadas, o que corresponde a 9,04\% dos 663 inscritos.
Com relação a esse número (composto por 300 residentes em reumatologia e estudantes de medicina), a grande maioria pertence aos Estados de Pernambuco (214) e São Paulo (167), sendo 315 sócios com títulos de especialista da Sociedade Brasileira de Reumatologia/Associação Médica Brasileira.

Com relação ao perfil dos reumatologistas, 37\% deles eram ligados às universidades e 37\% ligados ao serviço público, diferente do observado por Ciconelli $(20 \%)^{(2)}$. Observou-se, contudo, o comparecimento de $52 \%$ de reumatologistas autônomos e 10\% de residentes em reumatologia. No item relativo à principal razão de sua participação, verificou-se que $13 \%$ eram palestrantes, $59 \%$ buscavam obter conhecimentos clínicos aplicados à prática diária, $72 \%$ compareceram para adquirir recentes conhecimentos científicos básicos da reumatologia, 15\% para apresentar pôster e 37\% para encontrar amigos.

Foi classificada como boa/excelente por $86 \%$ dos participantes a escolha da cidade Muro Alto, Ipojuca, PE; 74\% dos inscritos elegeram as instalações do Centro de Convenções do Summerville Beach Resort como boa/ excelente; 79\% votaram as acomodações dos hotéis e 66\% dos que responderam acharam o sistema de transporte hotel/centro de convenções/hotel, como boa /excelente.

A Tabela 1 demonstra a avaliação das Jornadas feita pelos participantes.

A relevância das Jornadas para as necessidades do participante foi vista como muita/alta relevância por $63 \%$ dos que responderam ao questionário; $67 \%$ avaliaram a qualidade educacional oferecida como boa/excelente; $70 \%$ avaliaram a qualidade científica oferecida nas Jornadas como boa/excelente, o mesmo resultado alcançado no quesito qualidade das conferências oferecidas.

Os pôsteres foram avaliados por $75 \%$ como de qualidade boa/excelente. E 58\% avaliaram a qualidade dos simpósios satélites das indústrias farmacêuticas como boa/excelente.

A Tabela 2 demonstra a atitude dos participantes com relação à programação geral das Jornadas.

TABELA 1

OrganizaÇão das Jornadas

\begin{tabular}{lccccccc}
\hline Classificação & Comunicação & Taxas & $\begin{array}{c}\text { Formato } \\
\text { inscrição }\end{array}$ & $\begin{array}{c}\text { Programação } \\
\text { social }\end{array}$ & $\begin{array}{c}\text { Organização } \\
\text { geral }\end{array}$ & $\begin{array}{c}\text { Sinalização } \\
\text { final }\end{array}$ \\
\hline Boa/excelente & $57 \%$ & $44 \%$ & $47 \%$ & $74 \%$ & $74 \%$ & $71 \%$ \\
\hline
\end{tabular}


TABELA 2

ProgramaÇÃo geral das Jornadas

\begin{tabular}{ccccccc}
\hline Classificação & Parte científica & Parte educacional & Simpósios satélites & Rever amigos & Visitas stands & Eventos sociais \\
\hline Boa/excelente & $69 \%$ & $63 \%$ & $58 \%$ & $93 \%$ & $70 \%$ & $74 \%$ \\
\hline
\end{tabular}

Dos pôsteres enviados, 93\% preferem mandá-los via correio eletrônico. Finalmente, $83 \%$ dos que participaram do breakfast científico classificaram-no de boa/excelente qualidade.

Toda mudança tem início com o conhecimento de seu objetivo precípuo: o que se pretende mudar. Assim, as pré-condições mais importantes para se notear o trabalho de quem pretende interceder sobre algum aspecto da realidade, são: saber sobre o que se está trabalhando e o que se pretende fazer.

A avidez por informações é maior do que se pensa e varia na proporção do desejo de se tomar decisões. Com isto, uma das principais funções de uma Sociedade é regularizar a sua correspondência, atendendo adequadamente às informações solicitadas. Os associados têm um leque de preferências que diferem por variados motivos e em diferentes períodos.

Questionários requerem construção bastante cuidadosa e linguagem apropriada, pois estará sob o controle de quem o responde. Sendo assim, cada estudo representando a combinação do tópico a ser observado, da população e dos objetivos destinados, torna-o único.

O baixo índice de resposta pode apresentar várias explicações. Talvez, a mais racional seja a percepção da falta de retorno destes dados aos associados: em que estas respostas irão ajudar? E também por causa de nosso hábito de pouco participarmos politicamente das mudanças. Entretanto, vale ressaltar que a grande maioria ainda é composta por sócios titulares. Assim, temos de atrair, especialmente, os outros vários associados para tornarem-se titulares revelando o impacto em ter título de especialista.

A elaboração de um questionário pode ser convenientemente dividida em três partes, cada qual com suas peculiaridades, evitando-se, assim, que todos os indivíduos marquem o mesmo escore: 1) o tipo de informação pesquisada; 2) a estrutura da questão; e 3) a escolha das palavras.

Com 37\% dos reumatologistas ligados às universidades e serviços públicos e $52 \%$ atuando como profissionais liberais, temos uma visão da dimensão da influência da reumatologia: desde a formação profissional, para o estudante de medicina, até o outro extremo, nos aspectos sociais nas diversas unidades de saúde dos serviços públicos. Pode-se, assim, criar um campo fértil e adequado para o crescimento e para as mudanças pretendidas pela Sociedade Brasileira de Reumatologia.
Vê-se, pela razão de participação dos médicos, um equilíbrio entre adquirir conhecimentos clínicos visando sua atividade diária e conhecimentos científicos básicos para sua atualização. Estes fatos deverão ser considerados na elaboração das próximas programações científicas de Jornadas e Congressos, os quais são reforçados pelo comparecimento de $52 \%$ de reumatologistas autônomos.

Apesar da apresentação de pôster ter sido a principal razão para $15 \%$ dos participantes, $75 \%$ avaliaram a qualidade como boa/excelente, o que justifica maior dedicação pela comissão organizadora, estimulando apresentações através de prêmios ou participação em outros eventos científicos.

A comunicação direta antes do evento, salientando o impacto dos tópicos principais, bem como os valores das taxas e formas de inscrição, são pontos observados numa boa organização.

As conferências apresentando assuntos atraentes ainda constituem item importante na programação científica.

Observa-se como um dado importante para a participação dos médicos e o para o sucesso do evento, as condições estruturais do local escolhido - hotel sede e centro de convenção -, como também os atrativos da cidade.

Os simpósios satélites passam a serem considerados um espaço não somente para a indústria farmacêutica apresentar o seu produto, mas também para serem discutidas as diversas posições contrárias, enriquecendo as informações obtidas.

A visitação à exposição da indústria farmacêutica, as oportunidades para encontrar amigos e os eventos sociais devem merecer tratamento e tempo adequado, pois continuam sendo motivos decisivos para a participação.

Há pouca informação publicada sobre avaliação de eventos médicos. Entretanto, a sua leitura pode fornecer dados alternativos para explorar preferências em futuros eventos.

FERNANDO S. CAVALCANTI

Professor adjunto IV da disciplina de Reumatologia e mestre em Medicina Interna

Departamento de Medicina Clínica da Universidade Federal de Pernambuco

ÂNGELA B. DUARTE

Professora titular da disciplina de Reumatologia Departamento de Medicina Clínica da Universidade Federal de Pernambuco 
Avaliação da XVII Jornada Brasileira de Reumatologia e XVII Jornada Norte/Nordeste de Reumatologia

A Sociedade Brasileira de Reumatologia se sentiria honrada em você preencher este questionário sobre as Jornadas e entregá-lo na Secretária do evento. Assim nos ajudará na organização e melhoria nos próximos eventos da SBR.

Médico Reumatologista ligado a Universidade

Médico Reumatologista ligado ao Serviço Público

Médico Reumatologista autônomo

Médico Residente Reumatologia

Médico Residente

Estudante de Medicina

Outra (especifique)

Qual o seu Estado?

Qual a principal razão de sua participação nestes eventos?

Palestrando convidado

Adquirir recentes conhecimentos clínicos na reumatologia

Adquirir recentes conhecimentos científicos na reumatologia

Convidado da Indústria Farmacêutica

Apresentar pôster

Encontrar colegas/amigos

Localização das Jornadas - marque 1 (ruim) 5 (excelente).

Cidade

$1 \square 2 \square \quad 3 \square \quad 4 \square \quad 5 \square$

Centro de Convenções

$1 \square \quad 2 \square \quad 3 \square \quad 4 \square \quad 5 \square$

Acomodações do Hotel $1 \square 2 \square 3 \square \quad 4 \square \quad 5 \square$

Transporte

$1 \square 2 \square \quad 3 \square \quad 4 \square \quad 5 \square$

Opinião sobre a Organição das Jornadas - marque 1 (ruim) 5 (excelente).

Comunicação antes das Jornadas

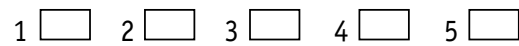

Taxas das Jornadas

$1 \square$

$2 \square$

$3 \square$

$4 \square$

Inscrição das Jornadas

$1 \square 2$

$3 \square$

Programação Social

$1 \square$

$2 \square$

$3 \square$

Organização Geral

das Jornadas

$$
1
$$
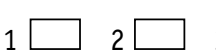

$3 \square$
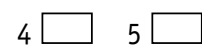

Livro da Programação

das Jornadas

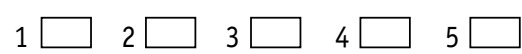

Sinalização das

salas/stands

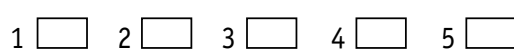

Como você avalia a relevância das Jornadas para suas necessidades?

$\begin{array}{ccccc}1 & 2 & 3 & 4 & 5 \\ \square & \square & \square & \square & \square \\ \begin{array}{c}\text { Sem } \\ \text { relevância }\end{array} & \begin{array}{c}\text { Pouca } \\ \text { relevância }\end{array} & \text { Relevante } & \begin{array}{c}\text { Muito } \\ \text { relevância }\end{array} & \begin{array}{c}\text { Alta } \\ \text { relevância }\end{array}\end{array}$

Como você avalia a qualidade educacional oferecida nestas Jornadas?

$\begin{array}{ccccc}1 & 2 & 3 & 4 & 5 \\ \square & \square & \square & \square & \square \\ \text { Pobre } & \text { Média } & \text { Satisfatória } & \text { Boa } & \text { Excelente }\end{array}$

\section{Como você avalia a qualidade científica oferecida nestas Jornadas?}

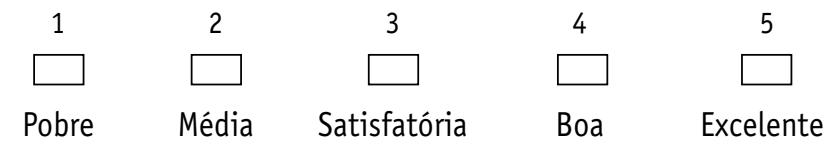

Como você avalia a qualidade das conferências oferecidas nestas Jornadas?

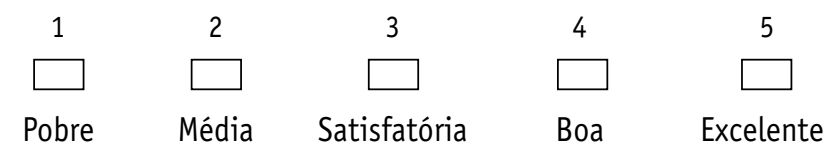

Como você avalia a qualidade dos pôsters apresentados nestas Jornadas?

$\begin{array}{ccccc}1 & 2 & 3 & 4 & 5 \\ \square & \square & \square & \square & \square \\ \text { Pobre } & \text { Média } & \text { Satisfatória } & \text { Boa } & \text { Excelente }\end{array}$

Como você avalia a qualidade dos simpósios satélites oferecidos nestas Jornadas?

$\begin{array}{ccccc}1 & 2 & 3 & 4 & 5 \\ \square & \square & \square & \square & \square \\ \text { Pobre } & \text { Média } & \text { Satisfatória } & \text { Boa } & \text { Excelente }\end{array}$


Qual sua opinião sobre o programa das Jornadas - marque 1 (ruim) 5 (excelente).

Programa Científico 1

2

3

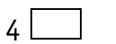

Programa Educacional

1

2

Simpósios Satélites

1

Oportunidade de encontrar amigos

Oportunidade de visitar stands

Eventos Sociais

Tempo para lazer$$
1
$$
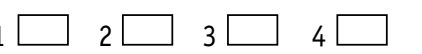

$5 \square$

Se sim: prefere envio por e-mail

houve boa comunicação com a secretaria

$\mathrm{s} \square \mathrm{N} \square$

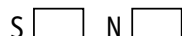

$\mathrm{s} \square \mathrm{N} \square$

Você participou do Breakfast Científico?

$\mathrm{s} \square \mathrm{N} \square$

Qual sua opinião sobre ele - marque 1 (ruim) 5 (excelente).

$1 \square 2 \square 3 \square \quad 4 \square$
$5 \square$

\section{REFERÊNCIAS}

1. Dillman D: Writing Questions. In: Mail and Telephone Survey: the total design method, Ed New York, Wiley, 1978:79-117.
2. Ciconelli RM: Perfil do Reumatologista Brasileiro, Bol Soc Bras Reumatol 1: 5, 2002. 